diese nach der ersten Fällung des Kermes einige Tage an dex Luft stehn, so setzl sich allmählig weisses Antimonoxydhydrat aus selbiger ab, und mit Säuren erscheinen dann nur Spuren eines dem Kermes gleichen Niederschlags. Man sieht also, dass die Ausscheidung von Oxyd bei der Kermesbereitung wirklich slatt findet; es betrug auf das Pfund Kalitmoxydcarbonal3 18,5 Gran.

\title{
Ueber die Wirkung der Salzsäure auf gewisse schwefelsaure Salze, und besonders auf schwefelsaures Kupferoxyd;
}

von

Robert Kane.

(The Lond. and Edinb. philos. Magaz. and Journal of Scienc. 3 Ser. VIII. 354. Auszng).

Wenn blauer Vitriol $(\dddot{\mathrm{S}}+\dot{\mathrm{C}} \mathrm{u}+5 \dot{\mathrm{H}})$ in Chlorwasserstoffsäure aufgelöst wird, so entsteht eine beträchtlicheTemperaturerniedrigung von $65^{\circ}$ F. zu ohngefähr $35^{\circ}$. Die Auflösung wird dunkeJgrün und giebt beim Verdampfen Krystalle von Kupferchloridhydrat. Wenn man eine dem Alomgewicht entsprechende Quantität schwefelsaures Kupferoxyd bei Erwärmen in einer Quantität flüssiger Chlorwasserstoffsäure aullüst, die einem Alom trockner Säure enlspricht, so gesteht das Ganze zu einer fasrigen Masse von Kupferchloridhydrat; alles schwefelsaure Kupferoxyd ist zersetzt und die Schwefelsäure in dem Wasser gelöst.

Ohnerachtet die Schwefelsäure sonst höher gestellt wird in ihren Affinitäten als die Chlorwasserstoffsäure, so wird sie doch hier völlig ausgetrieben. Das plölzliche Freiwerden der grossen Quantität des Wassers in dem schwefelsauren 
Kupferoxyde aus dem festen Zustande bedingt die merkwürdige Temperaturverringerung.

Mitunter habe ich beobachtet, dass wenn das krystallisirte Kupferchlorid einige Zeit mit der stark sauren Mutterlauge in Berührung bleibt, eine umgekehrte Wirkung statt findet, und kleine Krystalle von Sulfat in der Masse sich bilden. Ich habe diese Krystalle verschiedentlich unlersucht, um z.u bestimmen, ob sie ein Sulfat von Kupferchlorid gleich Peligot's Chromat von Kaliumchlorid; es liess sich keine bestimıte Zusammensetzung entdecken.

Zur Untersuchung der in Rede stehenden Reaction schien es von Wichligkeit, die Action des schwefelsauren Kupfers auf trocknes Chlorwasserstoffgas zu bestimmen.

Ueber feingepülvertes krystallisirtes schwefelsaures $\mathrm{Ku}$ pferoxyd wurde ein Strom getrocknetes Chlorwasserstoffgas geleitet. Unter starker Wärmeentwicklung wird das Gas absorbirt, und das Salz zu seidenglänzenden blassgriinen Krystallen. Einige Tropfen Feuchtigkeit erscheinen an dem kalten Theile der Röhre. An den erhitzten Stellen der Röhre sieht man Punkle einer chokoladebraunen Malerie. Nach Aufhören aller Reaction findet man, dass das schwefelsaure Kupferoxyd etwas mehr als ein Atom Cllorwasserstoffsäure absorbirt hat. Dieser Ueberschuss muss der duirch das entwickelte Wasser absorbirten Quantität zugeschrieben werden.

Die Masse dieser erhaltenen grünen Krystalle ist sehr zerfliesslich, sauer und stösst Dämpfe aus, wahrscheinlich wegen des Ueberschusses von Cllorwasserstoffsäure. Durch Umkrystallisiren exhält man daraus Kupferchloridhydrat in langen Nadeln.

Wenn man denselben Versuch anstellt mit wasserleeren schwefelsaurem Kupferoxyde, oder mit solchem, welches noch ein Atom Wasser enthält, so geben diese beiden Salze ein fast ganz gleiches Resultat. 
Beide Salze absorbiren rasch das Chlorwasserstoffgas und werden braun; es entwickelt sich dabei so viel Hitze, dass die Röhren oft reissen. Man muss das Gas noch lange nach dem Erkalten durchsirömen Jassen. Die Menge des absorbirten Gases ist fast genau ein Atom auf ein Nlom der Salze, wenigstens annähernd bis auf kaum ein Procent fehlend.

Die braune Materie besitzt interessante Eigenschaften. Wenn sie allmälig erhitzt wird, so verliert sie die Chlorwasserstoffsäure und es bleibt unveränderles schwefelsaures Kupferoxyd zurïck. Der Luft ausgesetzt, absorbirt sie Wasser unter Entwicklung von Wärme und wird apfelgrün, was augenblicklich statt findet, wenn man einige Tropfen Wasser darauf fallen lässt. In Wasser giebt sie cine apfelgrüne Auflösung, die durch Krystallisation krystallisirtes Kupferchlorid liefert, die Schwefelsäure bleibt in der Flïssigkeit.

Ueber die Nalur des so gebildeten Körpers lassen sich zwei Theorien aufstellen. Erstens : der Chlorwasserstoff wird von dem Kupfersulfate absorbirt, und verbindet sich damit in der Art wie Wasser solches thut, dass in der That die sogenannte Salzsäure fähig ist, das Krystallwasser von Salzen zu ersetzen, wie Ammoniak und Phosphorwassersioff, haben die Versuche von Rose und Graham gezeigt. Zweitens: der Chlorwasserstoff bildet bei seiner Reaction auf Kupferoxyd Wasser und Kupferchlorid, welches letzlere sich mit der Schwefelsäure zu einem Chloridsulfate verbindet.

Die allgemeinen Eigenschaften der braunen Materie machen es mir wahrscheinlich, dass der Chlorwasserstoff als solcher in dem braunen Pulver existirt, und dass das $\mathrm{Ku}$ pferchlorid sich nur bildet, wenn die Zersetzung bei Vorhandenseyn von Wasser bewirkt wird. 
Die hier angeführten besondern Resultate bewogen mich, das Verhalten der Chlorwasserstoffsäure gegen die Sulfate im Allgemeinen zu prüfen.

Schwefelsaures Kali, -Natron, - Zinkoxyd, Magnesia, -Eisenoxydul, -Alamerde, und -Bleioxyd wurlen durch darübergeleitetes Chlorwasserstoffgas nicht verändert. Schwefelsaures Nickeloxyd und Quecksilberoxyd absorbiren salzsaures Gas, unter Entwicklung von Wärme, nach Aufnahme eines halben Atoms hört die Absorbtion aber auf; durch Erhizen und an der Luft entweicht das Gas wieder; durch Wasser scheidet sich das reine Sulfat ab, und die Cllorwasserstoffsäure bleibt in dem Wasser.

Wenn man bei Mitwirkung von Wärme zwei Atome schwefelsaures Kali in flüssiger Chlorwasserstoffsäure auföst, die ein Atom reeller Säure enthäll, so scheiden sich beim Erkalten feine Krystalle $a b$, die doppeltschwefelsaures Kali sind, vermischt mit opaken Würfeln von Chlorkalium. Ich habe durch viele Analysen dieser Krystalle untersucht, ob das dem Chromate correspondirende Sulfat von Chlorkalium einige Existenz habe, jedoch immer vergebens. Doppeltschwefelsaures Kali krystallisirt aus seiner Aufösung in flüssiger Chlorwasserstoffsäure unverändert.

Schwefelsaures Ammoniak giebt, ähnlich behandelt, gleiche Resultate.

Es ist längst bekannt, dass Glaubersalz mit Chlorwasserstoffsäure eine kräftige kaltmachende Mischung bildet. Die Theorie darüber wird durch die Resultate des Versuchs gegeben. Beim Auflösen von schwefelsaurem Natron in Chlorwasserstoffsäure bilden sich doppeltschwefelsaures Natron und Chlornatrium, und da das erste Salz nur mit 4 Atomen Wasser krystallisirt, wird die übrigbleibende Menge des Krystallwassers des Glaubersalzes frei zum Betrage von 16 Atomen. Diese so bedeutende aus ihrem festen Zustande 
frei werdende Quantität Wasser bewirkt durch die Absorbtion des Wärmestoffs, um flüssig zu werden, die kaltmachende Eigenschaft.

Schwefelsaures Zinkoxyd und schwefelsaure Magnesia werden aus ilhrer Aulösung in Chlorwasserstoffsäure durch Abkühlen und Verdunsten unverändert wieder erhalten.

Die Auflösung von schwefelsaurem Eisenoxydul in Chlorwasserstoffsüure giebt durch Krystallisiren Quantitälen von unveränderlem Sulfat und Chloreisen. Zuweilen hat das Sulfat seine gewöhnliche Quantilät von Krystallwasser, oft enthält es aber nur 3 Atome. Die Krystalle des letztern Salzes sind so zusammengehäuft, dass ihre Form sich nicht bestimmen lässt; sie sind durchscheinend, härter und heller grün als das gewöhnliche Salz, beständig und ihre Auflösung in Wasser giebt das Sulfat mit der gewühnlichen Menge des Krystallwassers.

Die scliwefelsaure Alaunerde krystallisirt unverändert aus ihrer Auflösung in Chlorwasserstoff, aber in schönern Tafeln als aus Wasser.

Schwefelsaures Nickeloxyd und -Quecksilberoxyd krystallisiren aus ihrer Auflösung in Chlorwasserstoffsäure unverändert.

\title{
Ueber die Bereitung des Mineralkermes und des Antimongoldschwefels mittelst der Depla- cirungsmethode;
}

\author{
rom \\ Apotheker Musculus \\ zu Sulz am Niederrhein.
}

Die Deplacirungsmethode ist, so viel mir bekannt, bis jetzt nur auf die Ausziehung von Pllanzensubstanzen ange- 